\title{
Effects of Density, Temperature, Size, Grain Angle of Wood Materials on Nondestructive Moisture Meters ${ }^{1}$
}

\author{
Sung-Jun Pang ${ }^{2} \cdot$ Gi Young Jeong $\mathbb{D}^{2, \dagger}$
}

\begin{abstract}
The aim of this study was to investigate the effects of density, temperature, size, and grain direction on measurement of moisture contents (MC) of wood materials non-destructively. The MC of different sizes of solid wood, glulam, and CLT from larch (larix kaempferi, $560 \mathrm{~kg} / \mathrm{m}^{3}$ ) and pine (pinus koraiensis, $430 \mathrm{~kg} / \mathrm{m}^{3}$ ) were measured using the dielectric type and resistance type meters. The specimens were conditioned in the environmental chamber to be equilibrium moisture content (EMC) of $12 \%$ and $19 \%$. When density setting in dielectric type meter was increased from $400 \mathrm{~kg} / \mathrm{m}^{3}$ to $600 \mathrm{~kg} / \mathrm{m}^{3}$, the MCs of specimen (S-L-100-E) were decreased from $13.4 \%$ to $11.3 \%$. However, when wood group (WG) setting in resistance type meter was changed from WG1 to WG4, the measured MCs were increased from $9.2 \%$ to $12.3 \%$. When temperature setting in resistance type meters was changed from 0 to 35 ${ }^{\circ} \mathrm{C}$, the MC was decreased from $17.0 \%$ to $13.0 \%$. The MCs measured by dielectric type meter for larger specimens (S-L-100-E_11.3 \%, G-L-240-E_11.7 \% and C-L-120-E_12.8\%) were higher than those of small size specimens (S-L-30-E_8.7 \%, G-L-150-E_10.3 \%, and C-L-90-E_9.7\%). The MCs measured by resistance type meter for larger specimens (G-L-240-E_11.6 \% and C-L-120-E_13.3\%) were also higher than those of small size specimens (G-L-150-E_10.4\%, and C-L-90-E_11.8\%). The resistance type meter was not affected by the grain direction but the dielectric type meter were affected by the grain direction. The MC measured by resistance type meter for G-L-120-E perpendicular to grain direction was $11.5 \%$ and the measured MC parallel to grain direction was $11.3 \%$. The MC measured by dielectric type meter parallel to grain direction (12.1\%) was higher than that measured perpendicular to grain direction $(10.7 \%)$.
\end{abstract}

Keywords: moisture contents, cross-laminated timber, glulam, dielectric moisture meter, resistance meters, oven-dry method

\section{INTRODUCTION}

The stability of timber frame building is highly influenced by moisture content (MC) of structural members (Lee, 2016b). The structural health condition of the old timber building should be monitored by checking the MC of the structural member. The commercial MC meters provide a faster and easier evaluation of the MCs of wood-based products. The MC detected by the meter is affected by the wood

\footnotetext{
${ }^{1}$ Date Received October 1, 2018, Date Accepted December 21, 2018

2 Department of Wood Science and Engineering, Chonnam National University, 77 Yongbong-ro, Buk-Gu, Gwangju 61186, Republic of Korea

† Corresponding author: Gi Young Jeong (e-mail: gjeong1@jnu.ac.kr, ORCID: 0000-0003-2971-0631)
} 
characteristics, density, grain direction, and thickness of wood as well as the applied technologies in the MC meters.

In case of wood exposed to outdoor, it is easy to observe decay by fungi. Wood decay by fungi is related to the initial MC of wood as well as the characteristics of the fungi and the wood species (Kazemi et al., 2001). Nowadays, mechanical devices for detecting the wood decay are used to overcome the limitation of visual inspection (Son and Lee, 2004). The initial MC of wood is necessary to use the mechanical devices for detecting wood condition and helpful for maintaining the stable condition of timber structures.

Jung and Smith (1994) evaluated the EMC of red pine, eastern white pine, eastern hemlock, and Norway spruce dried by conventional kiln dry and high temperature dry. The specimens were equilibrated to $15 \%$ of the target EMC at $25{ }^{\circ} \mathrm{C}$ (relative humidity: $77 \%$ ) and the EMCs of the specimens were determined by using oven-dry method, resistance meter, and capacitive-admittance meter. The measured EMCs of specimens were affected by the species and the applied dry method. Moreover, the EMCs of specimens differed greatly between the MC measurement methods. The resistive meter is affected not only by the moisture inside wood but also by the chemical composition of the wood. Capacitive-admittance meter is influenced by the density as well as the moisture inside wood. When MC of wood is measured by the commercial MC meters, the user should know the characteristics of the MC meter and the wood species to reduce the measurement error.

It is difficult to measure MC of real wood member correctly due to the MC gradient inside the member (Kim et al., 2017). Especially, softwood have the higher MC gradient than the hardwood. Although oven-dry method is generally used for measuring MC of wood materials (Yang et al., 2017), the MC of wood members in timber frame building cannot be measured by oven-dry method. Moreover, the actual MC of wood in the outdoor is changed depending on the temperature and humidity (Ra, 2014; Ra, 2018). In this case, the nondestructive testing (NDT) method should be adopted. Commercial MC meters are made by using the principle of dielectric or resistance of moisture. The displayed MC on the commercial meter is affected by the setting conditions, temperature or density (Oh, 2016; Kang et al., 2017). Thus, the accuracy and sensitivity of the commercial moisture meters for domestic wood, especially exposed to outdoor for a long time, should be previously checked depending on the various setting conditions.

The purpose of this study was to evaluate MCs of wood products using NDT methods dielectric moisture meter and resistance meters. To measure the MCs of domestic wood products more reliably, the effects of setting conditions of the meters and characteristics of materials on MC measurement were analyzed.

\section{MATERIALS and METHODS}

\subsection{Specimens}

To investigate the relationship between the measured MCs and the characteristics of materials, three kinds of wood products, solid wood, glulam, and cross-laminated timber (CLT) were prepared. The wood products used in this study are from larch (larix kaempferi, $560 \mathrm{~kg} / \mathrm{m}^{3}$ ) and pine (pinus koraiensis, 430 $\mathrm{kg} / \mathrm{m}^{3}$ ). Fig. 1 shows types and orientations of the specimens. The sizes, species, and contacted plane of specimens were also considered. Table 1 shows the specimen nomenclature and the specimen conditions, type, species, size, and MC condition. The nomenclature of specimens were determined depending on the specimen type, species, a value of $\mathrm{X}$ dimension $(\mathrm{mm})$, and the MC of conditions. The first letter indicates the type of specimen (S: solid wood, G: glulam, and 


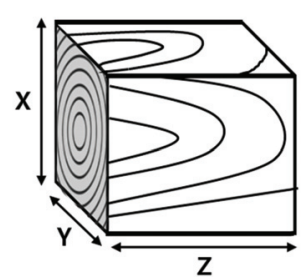

(a) Solid wood

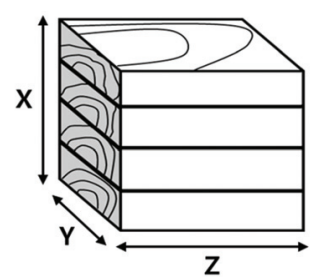

(b) Glued-laminated timber (glulam)

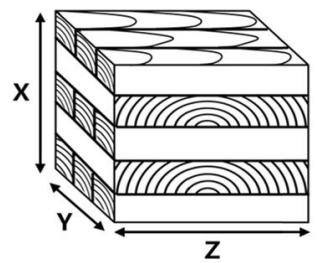

(c) Cross-laminated timber (CLT)

Fig. 1. Types and orientations of specimens.

Table 1. Nomenclatures of specimens depending on the specimen conditions

\begin{tabular}{|c|c|c|c|c|c|c|}
\hline \multirow{2}{*}{ ID } & \multirow{2}{*}{ Type } & \multirow{2}{*}{ Species } & \multicolumn{3}{|c|}{ Dimensions (mm) } & \multirow{2}{*}{ Condition } \\
\hline & & & $\mathrm{X}$ & $\mathrm{Y}$ & $\mathrm{Z}$ & \\
\hline $\begin{array}{l}S^{1)}-L^{2)}-30^{3)}-E^{4)} \\
S-L-30-S\end{array}$ & \multirow{4}{*}{ Solid wood } & \multirow[t]{2}{*}{ Larch } & 30 & 30 & 120 & $\begin{array}{c}\text { EMC } 12 \% \text { and } 19 \% \\
\text { Saturated }\end{array}$ \\
\hline S-L-100-E & & & 100 & 100 & 100 & EMC $12 \%$ and $19 \%$ \\
\hline $\begin{array}{l}\text { S-P-30-E } \\
\text { S-P-30-S }\end{array}$ & & \multirow[t]{2}{*}{ Pine } & 30 & 30 & 120 & $\begin{array}{c}\text { EMC } 12 \% \text { and } 19 \% \\
\text { Saturated }\end{array}$ \\
\hline S-P-100-E & & & 100 & 100 & 100 & EMC $12 \%$ and $19 \%$ \\
\hline G-L-120-E & \multirow{6}{*}{ Glued-laminated timber } & \multirow{3}{*}{ Larch } & 120 & 120 & 150 & EMC $12 \%$ and $19 \%$ \\
\hline G-L-180-E & & & 180 & 180 & 180 & EMC $12 \%$ and $19 \%$ \\
\hline G-L-240-E & & & 240 & 180 & 180 & EMC $12 \%$ and $19 \%$ \\
\hline G-P-120-E & & \multirow{3}{*}{ Pine } & 120 & 120 & 150 & EMC $12 \%$ and $19 \%$ \\
\hline G-P-180-E & & & 180 & 180 & 180 & EMC $12 \%$ and $19 \%$ \\
\hline G-P-240-E & & & 240 & 180 & 180 & EMC $12 \%$ and $19 \%$ \\
\hline C-L-90-E & \multirow{4}{*}{ Cross-laminated timber } & Larch & 90 & 90 & 90 & EMC $12 \%$ and $19 \%$ \\
\hline C-L-120-E & & Larch & 120 & 120 & 120 & EMC $12 \%$ and $19 \%$ \\
\hline C-P-90-E & & Pine & 90 & 90 & 90 & EMC $12 \%$ and $19 \%$ \\
\hline C-P-120-E & & Pine & 120 & 120 & 120 & EMC $12 \%$ and $19 \%$ \\
\hline
\end{tabular}

1) Type of wood product; $S=$ solid wood, $G=$ glulam, $C=$ cross-laminated timber.

2) Species; L=larch, $P=$ pine

3) Thickness of specimen $(\mathrm{mm})$.

4) Conditioning of specimen; E=specimen was conditioned to reach EMC of $12 \%$ and $19 \%$, S=specimen was immerged in water to reach saturation.

C: CLT). The second letter indicates wood species (L: larch, P: pine). The third number indicates the $\mathrm{X}$ dimension value which was the thickness of specimens. The 150, 180, and $240 \mathrm{~mm}$ thick glulam were consisted with 4, 6, and 8 layers and the thicknesses of all laminas in glulam was $30 \mathrm{~mm}$. The $90 \mathrm{~mm}$ thick CLT was consisted with 3 layers and the thicknesses of all laminas were $30 \mathrm{~mm}$. The $120 \mathrm{~mm}$ thick CLT was consisted with 5 layers and the thicknesses of outer and inner laminas were $30 \mathrm{~mm}$ and $20 \mathrm{~mm}$, respectively. The last letter indicates the MC conditions of specimens. EMC condition means that the specimens were stored at environmental chamber to be the target EMC (12 $\%$ or $19 \%)$. Saturated condition means that the 


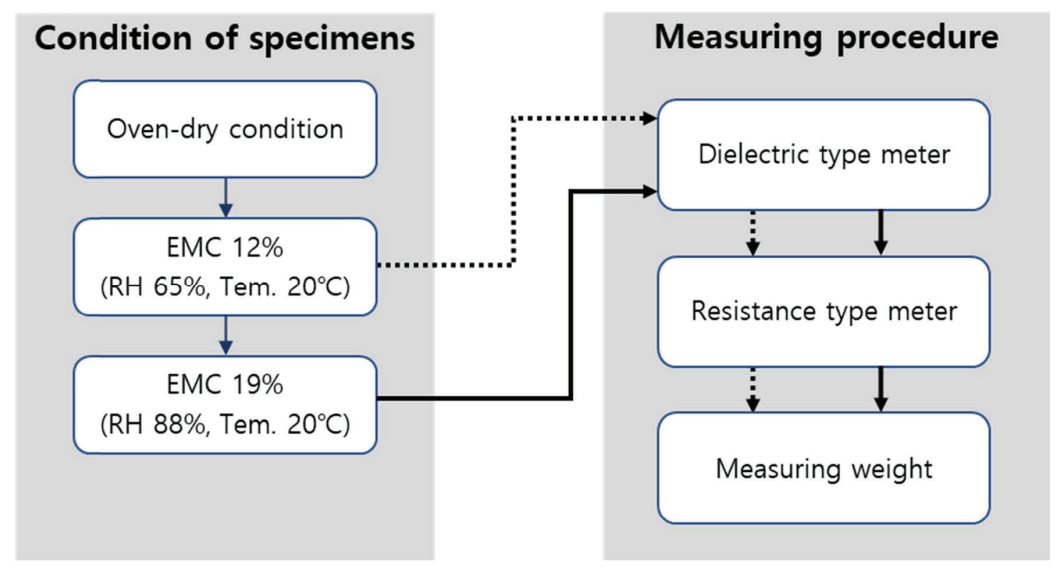

Fig. 2. Procedures for conditioning and measuring of moisture contents of specimens.

specimens were immersed in water to be over $30 \%$ MC.

\subsection{Conditioning of specimens}

Specimens of two groups, S-L-30-S and S-P-30-S, were immerged in water to reach saturation. The other specimens except for the two groups were conditioned in the environmental chamber with different $\mathrm{RH}$ at 20 ${ }^{\circ} \mathrm{C}$ to reach EMC of $12 \%$ and $19 \%$. Fig. 2 shows the procedure of conditioning steps for changing the $\mathrm{MC}$ of specimens and the measuring steps for detecting the MC of specimens. Each different conditioning period was determined by comparing weight changes of specimen every 3 days. If the specimen weight was changed less than $1 \%$, MC of specimens at the target condition was taken and moved to the next condition. The MC of specimens at EMC $12 \%$ and $19 \%$ was measured using two dielectric type moisture meters (MC-160 SA and MC-380 XCA, Exotek Instruments, Germany) and a resistance type meter (MC-460, Exotek Instruments, Germany). In order to derive the MC of all specimens by oven dry method (ASTM D 4442, 2007), the specimens weight was measured using a digital balance (HS 2100F, Hansung Ace Co., Seoul,
Korea) with a sensitivity of $0.01 \mathrm{~g}$.

\subsection{Measurement of moisture contents of specimens}

The dielectric type MC meter detects the dielectric changes due to the $\mathrm{MC}$ in a material using a high frequency digital signal (Exotek, 2013 a and b). The scanning depths for MC-160 SA and MC-380 XCA were $50 \mathrm{~mm}$ and $100 \mathrm{~mm}$, respectively. Fig. 3 (a) shows the schematic diagram to measure the MC of specimens by using the dielectric type moisture meters. The MCs of specimens were measured after the specimens were placed on the $50 \mathrm{~mm}$ thick polystyrene to avoid the influence of the basement material under the specimens.

The measuring probes of the meter were contacted the $\mathrm{X}-\mathrm{Y}$ plane and $\mathrm{X}-\mathrm{Z}$ plane (Fig. 1) of the test specimens and the probes were inclined in an approximately $40^{\circ}$ angle to the specimen. When the probes were contacted the $\mathrm{X}-\mathrm{Y}$ plane, the probes were arranged to the perpendicular to the longitudinal direction. When the probes were contacted the $\mathrm{X}-\mathrm{Z}$ plane, the probes were arranged to the parallel or perpendicular to the longitudinal direction. To check 


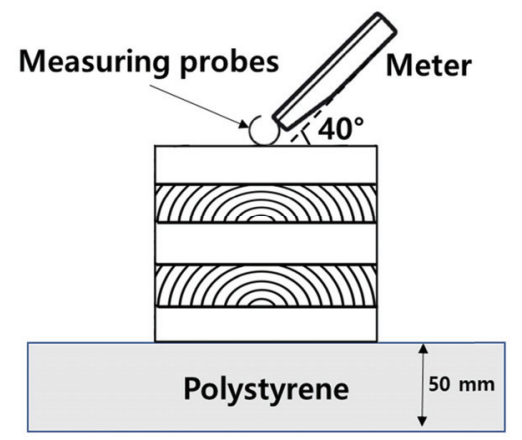

(a) Dielectric type

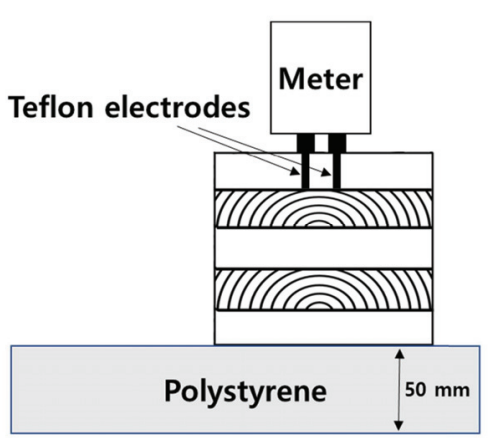

(b) Resistance type

Fig. 3. Schematic diagram to measure the moisture contents of specimens by using portable moisture meters.

the sensitivity of the MC meters by density, the MC of specimen was measured by changing the setting of wood density as 400,500 , and $600 \mathrm{~kg} / \mathrm{m}^{3}$ in the meters. All MC measurements were taken after 3 seconds.

The resistance type MC meter detect the resistance changes due to $\mathrm{MC}$ in a material using an electrical signal (Exotek, 2013 c). Fig. 3 (b) shows the schematic diagram to measure the $\mathrm{MC}$ of specimens by using the resistance type moisture meters. The $30 \mathrm{~mm}$ length of electrodes (from end point to $10 \mathrm{~mm}$ : no insulated, from $10 \mathrm{~mm}$ to $30 \mathrm{~mm}$ : teflon-insulated) were inserted to the surface of the specimen at the $\mathrm{X}-\mathrm{Y}$ plane and $\mathrm{X}-\mathrm{Z}$ plane (Fig. 1) in $90^{\circ}$ angle. When the electrodes were inserted into the $\mathrm{X}-\mathrm{Y}$ plane, the electrodes were arranged to the perpendicular to the longitudinal direction. When the electrodes were inserted into the $\mathrm{X}-\mathrm{Z}$ plane, the electrodes were arranged to the parallel or perpendicular to the longitudinal direction. To investigate the effects of density and temperature on MC measurement, different settings including 4 different wood group options (WG1, WG2, WG3, and WG4) and temperatures of $0,10,20,30,35{ }^{\circ} \mathrm{C}$ were used. The temperature of the testing room and environmental chamber was $20{ }^{\circ} \mathrm{C}$. The displayed MC of specimens was taken after 3 seconds.

To check the detectable penetration depth of dielectric type meter, four combinations were prepared as shown in Fig. 4. The four combinations were composed with the two grain directions (radial and tangential) and two MC conditions of contacted surface (12\% EMC and saturated MC).

\section{RESULTS and DISCUSSION}

\subsection{Sensitivity of moisture content meters}

Fig. 5 shows the results of the MCs measured by dielectric type meter (MC-380XCA) depending on its setting option (density). The measured MCs were decreased almost constantly as the setting value was increased.

When the setting of density was changed from 400 $\mathrm{kg} / \mathrm{m}^{3}$ to $600 \mathrm{~kg} / \mathrm{m}^{3}$, MC of S-L-100-E and MC of S-P-100-E measured parallel to the grain direction were changed from $13.4 \%$ to $11.3 \%$, and $11.8 \%$ to 9.7 $\%$, respectively. As the density setting was changed from $400 \mathrm{~kg} / \mathrm{m}^{3}$ to $600 \mathrm{~kg} / \mathrm{m}^{3}$, MC of S-L-100-E and MC of S-P-100-E measured perpendicular to the grain direction were changed from $12.1 \%$ to $9.7 \%$, and $10.5 \%$ to $8.5 \%$, respectively. In case of glulam, MC of G-L-240-E and MC of G-P-240-E measured parallel to the grain direction were changed from $13.7 \%$ to 


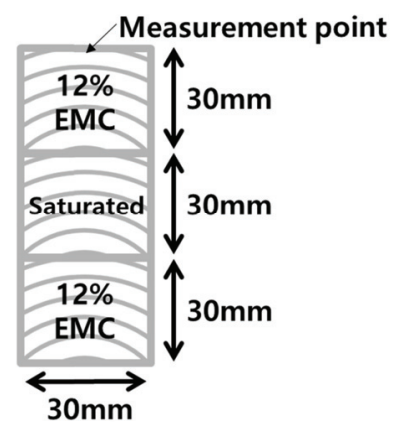

(a) Radial direction (12\%-Saturated-12\% combination)

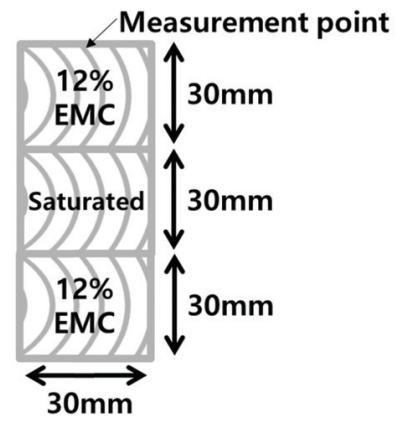

(c) Tangential direction (12\%-Saturated-12\% combination)

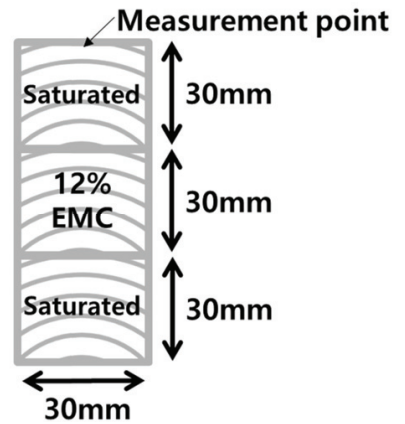

(b) Radial direction (Saturated-12\%-Saturated combination)

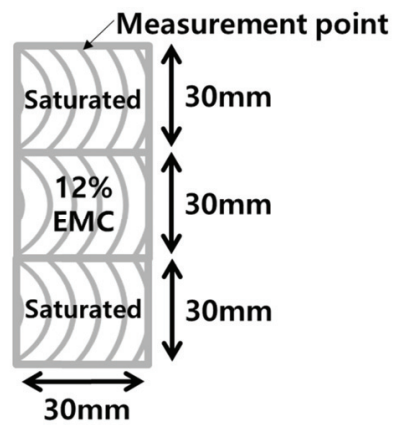

(d) Tangential direction (Saturated-12\%-Saturated combination)

Fig. 4. Combinations of specimens for evaluating the detectable depth of meters.

$11.0 \%$, and $10.9 \%$ to $8.9 \%$, respectively, while MC of G-L-240-E and MC of G-P-240-E measured perpendicular to the grain direction were changed from $11.9 \%$ to $9.7 \%$, and $8.9 \%$ to $7.1 \%$, respectively. In case of CLT, MC of C-L-120-E and MC of C-P-120-E measured parallel to the grain direction were changed from $12.5 \%$ to $10.0 \%$, and $10.3 \%$ to $8.3 \%$, respectively, and $\mathrm{MC}$ of C-L-120-E and MC of C-P-120-E measured perpendicular to the grain direction were changed from $11.4 \%$ to $9.0 \%$, and $8.8 \%$ to $6.8 \%$, respectively.

At the same setting value of density, the MC detected at the parallel to grain direction of specimen was higher than that detected at the perpendicular to grain direction of specimen. These results show that the density and the grain direction of wood products should be carefully considered to measure more accurate MC.
Figs. 6 and 7 show the results of the MCs measured by resistance type meter (MC-460) depending on its setting options (wood group and temperature). Fig. 6 shows that the effect of grain direction in resistance type meter was less than the dielectric type meter. The measured MCs were not much different depending on the grain direction of the specimen (G-L-120-E). The measured $\mathrm{MC}$ at perpendicular to grain direction $(\mathrm{X}-\mathrm{Z}$ plane) was $11.5 \%$ and the measured $\mathrm{MC}$ at parallel to grain direction (X-Z plane) was $11.3 \%$ at WG3 setting option. The measured MC perpendicular to glue line direction (X-Y plane) was $11.7 \%$ and the measured MC parallel to glue line direction ( $\mathrm{X}-\mathrm{Y}$ plane) was $11.5 \%$ at WG3 setting option.

The MC-460 provides the wood group options which represent some wood species instead of wood density values. For example, African zebrawood, imbula, noble 


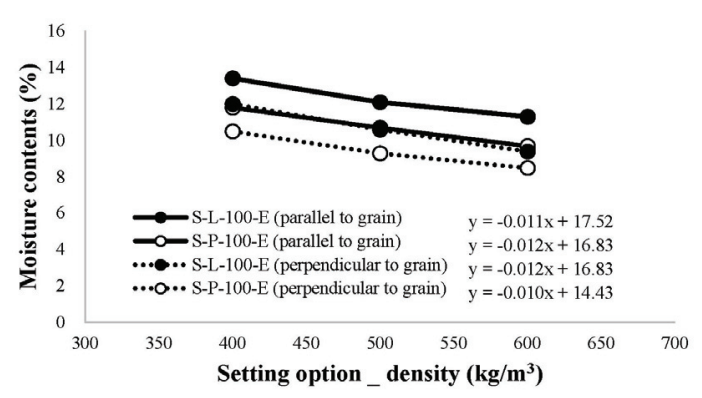

(a) Solid wood

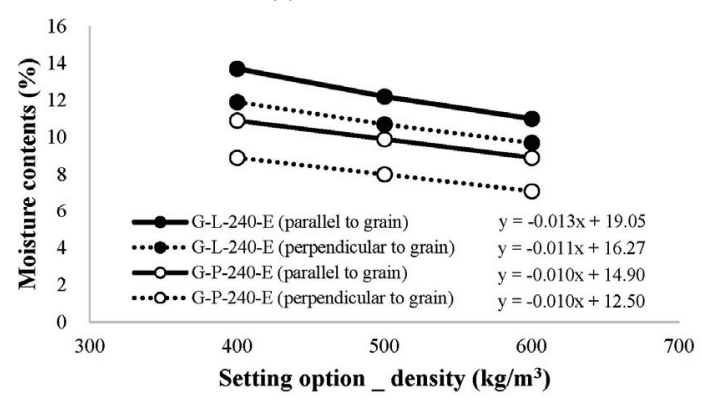

(b) Glued laminated timber

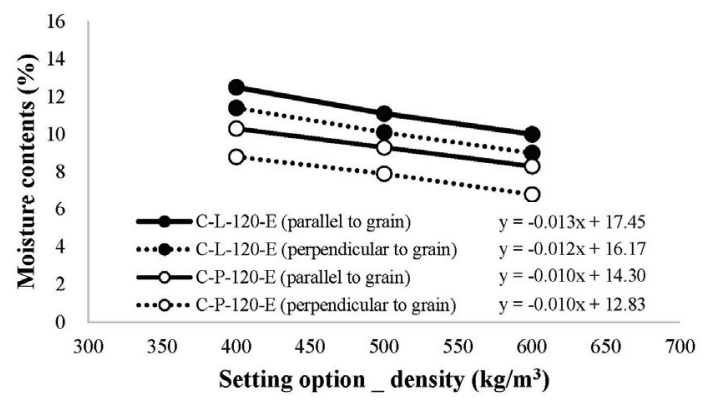

(c) Cross-laminated timber

Fig. 5. Moisture contents depending on the contacted grain direction and species, as well as the wood group options in MC-380XCA (Condition of environmental chamber: EMC 12 \% Temperature of testing room: $\left.20{ }^{\circ} \mathrm{C}\right)$.

fir, and tchitola wood are a group of WG1. Afzelia, beech, cedar, and teak wood are in WG2. Hemlock, larch, pine, and oak wood are in WG3. Bubinga, sipo, and tiama wood are in WG4. The MCs measured by changing the setting groups were changed almost constantly as a slope of approximately 1.1. When the

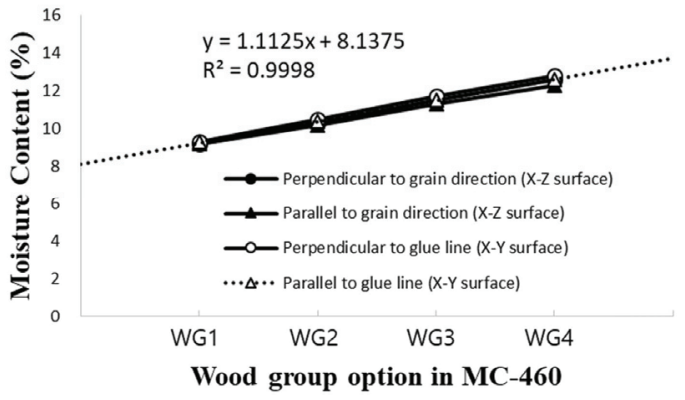

Fig. 6. Moisture contents depending on the contacted surface and grain direction of specimen, as well as the wood group options in MC-460 (G-L-120-E specimen, Condition of environmental chamber: EMC $12 \%$, Condition of temperature setting of the meter: $20{ }^{\circ} \mathrm{C}$, Temperature of testing room: $20{ }^{\circ} \mathrm{C}$ ).

setting of density was changed from WG1 to WG4 at $20{ }^{\circ} \mathrm{C}$ and EMC $12 \%$ conditions, the $\mathrm{MC}$ of G-L-120-E was increased from $9.2 \%$ to $12.3 \%$ measured parallel to grain direction (X-Z surface) and from $9.2 \%$ to $12.6 \%$ measured perpendicular to grain direction (X-Z surface). When the MCs were measured along to the glue line on the $\mathrm{X}-\mathrm{Y}$ surface or perpendicular to the glue line by changing the setting of density from WG1 to WG4 at $20{ }^{\circ} \mathrm{C}$, the MC of G-L-120-E was increased from $9.3 \%$ to $12.6 \%$ measured parallel to glue line and from $9.3 \%$ to 12.8 $\%$ measured perpendicular to glue line.

Fig. 7 shows that the effect of temperature option in MC-460. The measured MCs were decreased as the temperature setting value was increased. All of the MC were measured at perpendicular to the grain direction. In case of S-L-100-E and S-P-100-E species, when the temperature setting was changed from 0 to $35{ }^{\circ} \mathrm{C}$, the measured MC decreased from $17.0 \%$ to $13.0 \%$ and from 17.4 to $13.5 \%$, respectively. In case of larch and pine glulam, when the temperature setting was changed from 0 to $35{ }^{\circ} \mathrm{C}$, the measured MC decreased from $13.9 \%$ to $10.5 \%$ and from 12.6 to $9.2 \%$, respectively. In case of larch and pine CLT, when the 


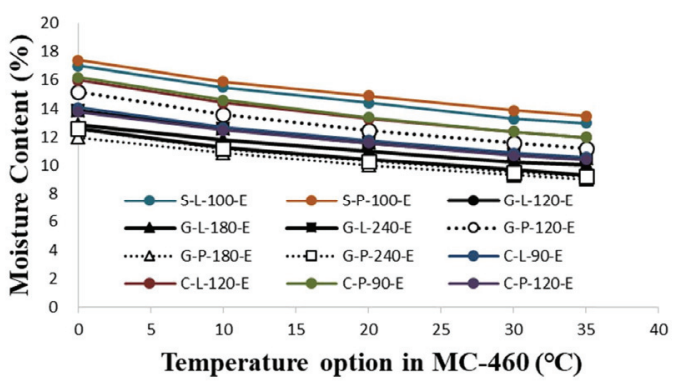

Fig. 7. Moisture contents of wood materials depending on the temperature option in MC-460 (Condition of environmental chamber: EMC $12 \%$, Condition of wood group setting: WG3, Temperature of testing room: $20{ }^{\circ} \mathrm{C}$ ).

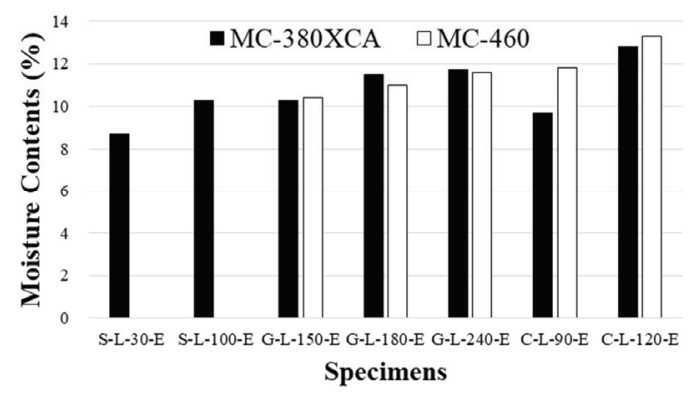

Fig. 8. Moisture contents depending on the specimen volume (Condition of environmental chamber: EMC $12 \%$, Conditions of density setting for MC-380XCA: $500 \mathrm{~kg} / \mathrm{m}^{3}$, Conditions of wood group and temperature setting for MC-460: WG3 and $20{ }^{\circ} \mathrm{C}$, Temperature of testing room: $20{ }^{\circ} \mathrm{C}$ ).

temperature setting was changed from 0 to $35{ }^{\circ} \mathrm{C}$, the measured MC decreased from $16.0 \%$ to $12.0 \%$ and from 13.8 to $10.4 \%$, respectively. When the temperature setting was changed from 0 to $35{ }^{\circ} \mathrm{C}$, the differences of measured MC occurred approximately $3 \sim 4 \%$.

At the same setting condition (WG3, $20{ }^{\circ} \mathrm{C}$ ), the measured MC for larch and pine species was not much different at the same grain direction. The MC of larch glulam (G-L-120-E) parallel to grain direction was 11.3

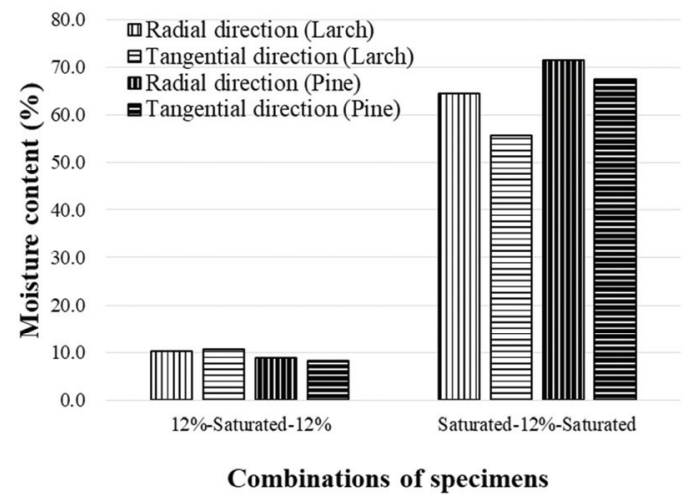

Fig. 9. Moisture contents detected by dielectric type meters (MC-380XCA) for combinations of specimens which have different moisture content (Conditions of density setting: $500 \mathrm{~kg} / \mathrm{m}^{3}$, Temperature of testing room: $20{ }^{\circ} \mathrm{C}$ ).

$\%$ and the MC of pine glulam (G-P-120-E) at the same grain direction was $11.7 \%$. The MC of larch CLT (C-L-90-E) parallel to grain direction was $11.6 \%$ and the MC of pine CLT (C-P-90-E) at parallel to grain direction was also $11.6 \%$.

The measured MCs using the resistance type meter was dependent on temperature but not dependent on grain direction.

\subsection{Effect of material size and detectable range of the moisture content meters}

The difference between inside MC and outside MC could be larger in the big size wood. This implies that the size of the wood may affect the MC measured by meters.

To analyze the feasibility of the detectable depth for moisture content measurement using meters, different sizes of specimens were tested. Fig. 8 shows that the MCs measured by dielectric type (MC-380XCA) after conditioning to EMC of $12 \%$ were affected by the specimen sizes. The measured MCs of larger specimens 


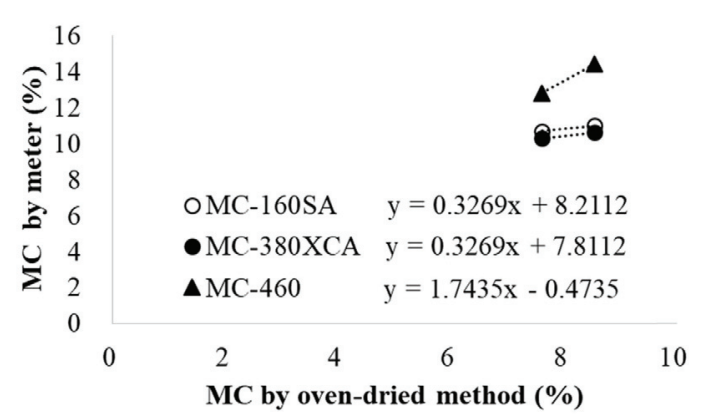

(a) Solid wood (S-L-100-E)

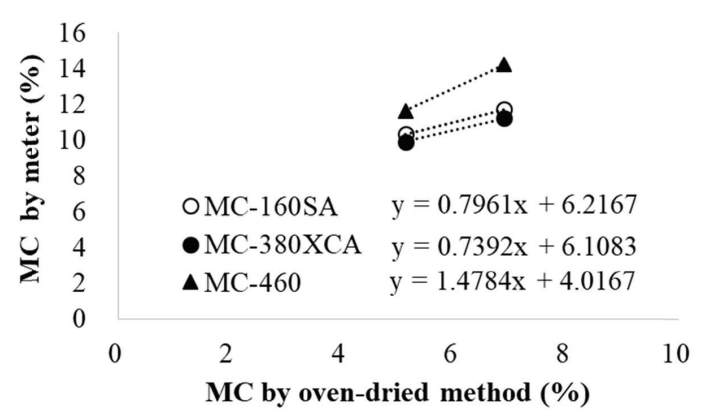

(b) Glulam (G-L-240-E)

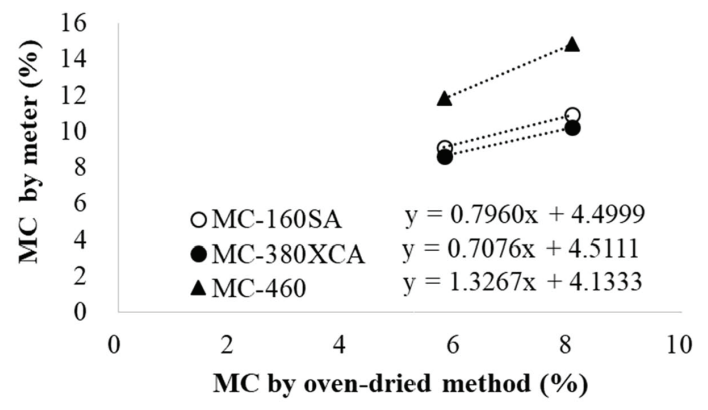

(c) Cross-laminated timber (C-L-90-E)

Fig. 10. Comparisons of moisture contents depending on measuring methods (Conditions of density setting for MC-160SA and MC-380XCA: $500 \mathrm{~kg} / \mathrm{m}^{3}$, Conditions of wood group and temperature setting for MC-460: WG3 and $20{ }^{\circ} \mathrm{C}$, Temperature of testing room: $20{ }^{\circ} \mathrm{C}$ ).

(S-L-100-E_11.3 \%, G-L-240-E_11.7 \% and C-L-120-E _12.8\%) were higher than those of small size specimens (S-L-30-E_8.7 \%, G-L-150-E_10.3 \%, and C-L-90-E_9.7 \%). In case of resistance type meter (MC-460), the measured
MCs of larger specimens (G-L-240-E_11.6 \% and C-L-120-E_13.3 \%) were also higher than those of small size specimens (G-L-150- E_10.4 \%, and C-L-90-E_11.8 $\%)$. The difference of MC depending on the specimen size was consistent with the results of Fredriksson et al. (2015). They theoretically calculated the electric potential differences depending on size of specimen, and explained that as the specimen volume becomes smaller, the electrical resistance becomes larger. Therefore, when the MC was measured on a small specimen, a low MC was obtained.

To evaluate the detectable penetration depth of dielectric type meter, four combinations were composed using S-L-30-E (12 \% EMC) and S-L-30-S (saturated) specimens (Fig. 4). Four combinations were reflected the grain directions (radial and tangential) and MCs of contacted surface (12\% EMC and saturated MC). MC meter does not reflect the MC at depths of 30 $\mathrm{mm}$ or more regardless of the grain direction. The measured MC was determined from the MC of the contacted area less than $30 \mathrm{~mm}$ detectable depth. These results indicate that the dielectric type meter measured the MC near the contacted surface only. Therefore, it would be better to use a resistance type meter together to measure the internal MC of a wood member.

\subsection{Differences of measured moisture content by different detecting methods}

Fig. 10 shows that the sensitivity of commercial MC meters according to the MC changes of specimens which measured by the oven-dried method. The change of MC of specimen was measured by MC-460 more sensitive than dielectric type meters (MC-160 SA, MC-380 XCA). It should be noticed that the MC measured by the MC meters was closer to the target EMC of environmental chamber than the MC measured by oven-dried method. Although the hygroscopicity of 
Effects of Density, Temperature, Size, Grain Angle of Wood Materials on Nondestructive Moisture Meters

the oven-dried specimens may have been decreased (Kang et al., 2018), the differences between MCs measured by oven-dry method and MC meter were more clearly appeared. In oven-dry method, the measured MC shows the averages MC of the specimens, because the $\mathrm{MC}$ of specimen was calculated by the weight difference of the specimen. On the other hand, for commercial MC meters, the MC was measured from the detectable depth of specimens.

In timber structure, the surface MC of a wood member exposed to the ambient air is changed based on the local climate. A large timber member has different MC in outer and inner sides of the cross section (Niemz and Mannes, 2012; Lee et al., 2016a). Thus, it is difficult to assume that the MC measured by the oven-dry method represents real situation of the timber member. This test result shows that the commercial MC meters also have a limitation which only provides the outside MC of timber member. However, in terms of providing accurate MC information of timber member, the outside MC is important, because it shows the status of timber member influenced by the local climate changes.

\section{CONCLUSION}

The effects of density, temperature, size, grain direction on measurement of MC of wood materials nondestructively were investigated. The sensitivities of dielectric type meter and resistance type meter were also investigated.

In case of dielectric type meter, the MCs of wood (S-L-100-E) were decreased from $13.4 \%$ to $11.3 \%$ when the density setting was increased from $400 \mathrm{~kg} / \mathrm{m}^{3}$ to $600 \mathrm{~kg} / \mathrm{m}^{3}$. The measured MCs of larger specimens (S-L-100-E_11.3 \%, G-L-240-E_11.7 \% and C-L-120E_12.8 \%) were higher than those of small size specimens (S-L-30-E_8.7 \%, G-L-150-E_10.3 \%, and C-L-90-E_9.7 $\%)$. The measured $\mathrm{MC}$ at the parallel to grain direction
(12.1 \%) was higher than that measured at the perpendicular to grain direction (10.7\%).

In case of resistance type meter, when the wood group (WG) was changed from WG1 to WG4, the MCs were increased $9.2 \%$ to $12.3 \%$. When the temperature setting was changed from 0 to $35{ }^{\circ} \mathrm{C}$, the MC was decreased from $17.0 \%$ to $13.0 \%$. At the same setting condition (WG3, $20{ }^{\circ} \mathrm{C}$ ), the measured MC for larch species (G-L-120-E_11.3 \%) and pine species (G-P-120-E_11.7 $\%)$ was not much different parallel to grain direction. The measured MCs of larger specimens (G-L-240E_11.6 \% and C-L-120-E_13.3 \%) were higher than those of small size specimens (G-L-150-E_10.4 \%, and C-L-90-E_11.8 \%). The measured MCs were not much different depending on the grain direction of the specimen.

\section{ACKNOWLEDGMENT}

This research supported by Basic Science Research Program through the National Research Foundation of Korea (NRF) funded by the Ministry of Education (No.2017R1D1A1B04033518).

\section{REFERENCES}

ASTM D 4442. 2007. Standard test methods for direct moisture content measurement of wood and woodbase materials In: Annual book of ASTM standard, sect 4, vol 04.10 Wood. American Society for Testing and Materials (ASTM), West Conshohocken, PA.

Exotek. 2013a. User's manual for MC-160SA. Exoteck instruments. www.exotek-instrucments.com.

Exotek. 2013b. User's manual for MC-380XCA. Exoteck instruments. www.exotek-instrucments.com.

Exotek. 2013c. User's manual for MC-460. Exoteck instruments. www.exotek-instrucments.com.

Fredriksson, M., Claesson, J., Wadsö, L. 2015. The 
influence of specimen size and distance to a surface on resistive moisture content measurements in wood. Mathematical Problems in Engineering, Mathematical Problems in Engineering, Article ID 215758: 1-7. http://dx.doi.org/10.1155/2015/215758 Jung, H.S., Smith, W.B. 1994. Comparison of equilibrium moisture contents for conventional kiln dried- and high temperature dried softwood lumber by moisture content determination. Journal of the Korean Wood Science and Technology 22(4): 37-42.

Kang, C.W., Jang, E.S., Jang, S., Kang, H.Y., Li, C., Choi, I.G. 2018. Changes of air permeability and moisture absorption capability of the wood by organosolv pretreatment. Journal of the Korean Wood Science and Technology 46(6): 637-644.

Kang, C.W., Lim, H.M., Kang, H.Y. 2017. Estimation of wood oven-dry density by using a portable dielectric moisture meter. Journal of the Korean Wood Science and Technology 45(5): 629-639.

Kazemi, S.M., Dickinson, D.J., Murphy, R.J. 2001. Effects of initial moisture content on wood decay at different levels of gaseous oxygen concentrations. Journal of Agricultural Science and Technology 3:293-304.

Kim, H.B., Han, Y., Park, Y., Yang, S.Y., Chung, H., Eom, C.D., Lee, H.M., Yeo, H. 2017. Finite difference evaluation of moisture profile in boxed-heart large-cross-section square timber of pinus densiflora during high temperature derying. Journal of the Korean Wood Science and Technology 45(6): 762-771.

Lee, C.J., Lee, N.H., Oh, S.W. 2016a. Effects of the knife-incising and kerfing pretreatment on moisture content and surface check occurrence of douglas-fir heavy timber. Journal of the Korean Wood Science and Technology 44(3): 302-314.

Lee, M., Park, S.B., Lee, S.M. 2016b. Comparison of moisture absorption/desorption properties of carbonized boards made from wood-based panels. Journal of the Korean Wood Science and Technology 44(3): 424-429.

Niemz, P., Mannes, D. 2012. Non-destructive testing of wood and wood-based materials. Journal of Cultural Heritage 13(3): S26-S34.

Oh, S.W. 2016. Electrical properties and far-infrared ray emission of ceramics manufactured with sawdust and rice husk. Journal of the Korean Wood Science and Technology 44(1): 106-112.

Ra, J.B. 2014. Determination of equilibrium moisture content of outdoor woods by using hailwoodhorrobin equation in Korea. Journal of the Korean Wood Science and Technology 42(6): 653-658.

Ra, J.B. 2018. Determination of moisture index in Korea. Journal of the Korean Wood Science and Technology 46(4): 301-308.

Son, D.W., Lee, D.H. 2004. Wood decay detection by non-destructive methods. Journal of the Korean Wood Science and Technology 32(4): 74-81.

Yang, I., Kim, S.H., Han, G.S. 2017. Effect of moisture content of sawdust and length to diameter ratio of a hole in flat-die pelletizer on the fuel characteristics of wood pellets produced with quercus mongolica, pinus densiflora, pinus rigida and larix kaempferi. Journal of the Korean Wood Science and Technology 45(4): 382-398. 